\title{
Comparing different boosters of planning interventions on changes in fat consumption in overweight and obese individuals: A randomized controlled trial
}

\author{
Urte Scholz ${ }^{1}$, Sibylle Ochsner ${ }^{2}$, and Aleksandra Luszczynska ${ }^{3}$ \\ ${ }^{1}$ Department of Psychology, University of Konstanz, Konstanz, Germany \\ ${ }^{2}$ Department of Psychology, University of Zurich, Zurich, Switzerland \\ ${ }^{3}$ Trauma, Health, and Hazards Center, University of Colorado, Colorado Springs, CO, USA
}

\begin{abstract}
ingle planning interventions have been found to promote short term dietary change. Repeated planning $\mathcal{W}$ interventions may foster long term effects on behavior change. It remains unknown whether there is a critical number of boosters to establish long term maintenance of behavioral changes. This study aimed at investigating what social cognitive variables mediate the effects of the interventions on dietary behavior change. Overall, 373 participants ( $n \quad 270$ women, $72.4 \%$; age $M \quad 52.42, S D \quad 12.79$ ) were randomly allocated to one of five groups: a control group, a single planning group, and three groups with 3,6, or 9 weeks' repeated planning interventions. Follow ups took place 4, 6, and 12 months after baseline. Change in fat consumption was not promoted by any of the interventions. In terms of social cognitive variables, intentions, self efficacy and coping planning displayed a time $\times$ group interaction, with the 9 weeks' planning group showing the most beneficial effects. Effect sizes, however, were very small. None of the tested planning interventions successfully promoted change in fat consumption across the 12 month period. This, however, could not be explained by problems with adherence to the intervention protocol. Potential explanations for this unexpected result are discussed.
\end{abstract}

\section{Keywords: Planning; Intervention; Diet; Overweight.}

1 a été établi que des interventions de planification uniques favorisent les changements à court terme des régimes diététiques. Les interventions de planification répétées pourraient produire des effets à long terme sur le changement de comportement. On ne sait toujours pas s'il y a un nombre critique de relances pour établir le maintien à long terme de changements comportementaux. De plus, notre recherche avait pour but de trouver quelles variables sociocognitives sont médiatrices par rapport aux effets des interventions sur le changement de comportement diététique. Au total, 373 participants ( $n \quad 270$ femmes, $72.4 \%$; âge $M \quad 52.42, E T \quad 12.79$ ) ont été répartis aléatoirement dans l'un de cinq groupes : un groupe contrôle, un groupe à planification unique et trois groupes à interventions planifiées répétées de trois, six et neuf semaines. Des suivis ont eu lieu à quatre, six et 12 mois de la mesure de la ligne de base. Aucune des interventions ne faisait la promotion d'un changement dans la consommation de gras. En termes des variables sociocognitives, les intentions, l'auto efficacité et la planification pour faire face ont donné une interaction temps par groupe, le groupe de planification de neuf semaines démontrant le plus d'effets bénéfiques. Toutefois, la grandeur des effets était très petite. Aucune des interventions planifiées n'a réussi à promouvoir un changement réussi pour la consommation de gras sur la période étudiée de 12 mois. Cela, toutefois, n'a pu être expliqué par des problèmes d'adhésion au protocole d'intervention. Nous discutons d'explications possibles de ces résultats inattendus.

Correspondence should be addressed to Urte Scholz, Department of Psychology, University of Konstanz, PO Box 5560/Box 14, 78457 Konstanz, Germany. (E mail: urte.scholz@uni konstanz.de).

This study was funded in part by the "Stiftung Suzanne und Hans Biäsch zur Förderung der Angewandten Psychologie". We would like to thank all students and interns who helped with data collection. While preparing this manuscript the first author was funded by the Swiss National Science Foundation (PP00P1_133632/1). 
S e ha encontrado que las intervenciones de planificación aisladas promueven cambios en la dieta a corto $\checkmark$ plazo. Las intervenciones reiteradas de planificación pueden fomentar efectos a largo plazo en el cambio de comportamiento. Aún se desconoce si hay una cantidad crítica de estímulos para establecer el mantenimiento de los cambios de comportamiento a largo plazo. Además, se tuvo como objetivo investigar cuáles son las variables sociocognitivas que median los efectos de las intervenciones en el cambio de comportamiento dietario. En total, 373 participantes (n 270 mujeres, 72,4\%; edad M 52,42; DE 12,79) fueron asignados aleatoriamente a uno de cinco grupos: un grupo control, un grupo de planificación única, y tres grupos de tres, seis o nueve semanas de intervenciones repetidas de planificación. Se llevaron a cabo seguimientos al cabo de cuatro, seis y doce meses después de la medida de base. El cambio en el consumo de grasa no fue promovido por ninguna de las intervenciones. En términos de las variables sociocognitivas, las intenciones, la autoeficacia y la planificación del afrontamiento mostraron una interacción de tiempo por grupo, siendo los efectos más beneficiosos para el grupo de planificación de nueve semanas. Los tamaños de efecto, sin embargo, fueron muy pequeños. Ninguna de las intervenciones de planificación puestas a prueba promovió con éxito el cambio en el consumo de grasa a lo largo del período de doce meses. Esto, sin embargo, no pudo ser explicado por problemas en la adhesión al protocolo de intervención. Se discuten las posibles explicaciones para este inesperado resultado.

Overweight and obesity are increasing rapidly worldwide. Consequences are severe, as increased body weight is related to higher morbidity and mortality (World Health Organisation, 2000). Treatment of overweight and obesity always entails a change in nutrition behavior (e.g., reducing fat intake; National Institutes of Health, 1998). As short-term dieting might be counterproductive in terms of weight loss in the long run (Mann et al., 2007), long-term changes in dietary habits are to be aimed for. Changing and maintaining health behavior in general, and dietary habits in particular, seems to be a major challenge that most people fail to master (e.g., Kumanyika et al., 2000).

\section{THEORETICAL BACKGROUND: THE HEALTH ACTION PROCESS APPROACH}

The theoretical framework of the present study was the health action process approach (HAPA; Schwarzer, 2008). In contrast to other theories of health behavior, such as the theory of planned behavior (Ajzen, 1991), the HAPA explicitly distinguishes between a motivational phase of intention formation and a volitional phase of translating the intentions into behavior. Risk awareness, outcome expectancies (i.e., the perceived advantages and disadvantages of a behavioral change), and self-efficacy (Bandura, 1997) are specified as predictors of intentions. Intentions, self-efficacy, action control, action planning, and coping planning are specified as predictors of behavior. Self-efficacy refers to the perceived competence to master a behavioral change (Bandura, 1997). Action control consists of three subfacets: awareness of own standards, self- monitoring, and self-regulatory effort (Sniehotta et al., 2005).

Action planning (also known as implementation intentions) refers to plans that link situational cues, specified in an if-component, to behavioral outcomes, specified in a then-component (Gollwitzer \& Sheeran, 2006). Coping planning, in turn, refers to the anticipation of personal barriers that might hinder goal achievement and the strategic planning on how to overcome these barriers in order to act in accordance with one's intentions (Sniehotta, Scholz, \& Schwarzer, 2006). Coping planning may prompt goal achievement over and above the effects of action planning alone (Sniehotta et al., 2006).

\section{PLANNING INTERVENTIONS AND LONGER-TERM MAINTENANCE OF BEHAVIORAL CHANGE}

Several studies demonstrated the effectiveness of a planning intervention on changes in fat intake (e.g., Armitage, 2004; Luszczynska, Scholz, \& Sutton, 2007; Prestwich, Ayres, \& Lawton, 2008). Most studies examining the effects of planning, however, focus on short-term effects (i.e., 1 to 2 weeks or 1 to 2 months after baseline), which is in contrast to the desired maintenance of dietary changes. Only a few studies investigate the effects of planning over a longer period of time. Luszczynska and colleagues (2007) demonstrated that a single face-to-face planning intervention for myocardial infarction patients resulted in lower saturated fat intake 8 months later. Other studies, however, pointed out that planning interventions on single occasions seem to be insufficient to promote longer-term maintenance of behavior change (e.g., Scholz, Knoll, Sniehotta, \& Schwarzer, 
2006). Although effects of single planning interventions may be negligible in the long run, reminders of plans (e.g., Prestwich, Perugini, \& Hurling, 2010) or repeated planning interventions (e.g., Chapman \& Armitage, 2010; Luszczynska \& Hayes, 2009; Scholz et al., 2006) may strengthen longer-term intervention effects. In previous studies participants were enrolled in the planning intervention three (Luszczynska \& Hayes, 2009), two (Chapman \& Armitage, 2010) or six times (Scholz et al., 2006), which resulted in successful maintenance of behavior change after 4, 6, and 12 months, respectively. It remains unknown whether there is a critical number of repetitions of the planning intervention that needs to be met in order for the long-term maintenance of changes in eating patterns to be established on a more habitual level. More precisely, it might either be that the more repetitions the better or that after a certain number of repetitions, there is no added value of extending the intervention. Thus, testing for the critical number of repetitions of planning interventions was the first aim of the present study.

\section{MEDIATORS OF PLANNING EFFECTIVENESS}

The examination of potential social-cognitive mediators of repeated planning interventions was the second aim of the present study. As Michie and Abraham (2004) point out, identifying the mechanisms that make interventions work is essential for our understanding of behavior change. The implementation intentions paradigm assumes specific mediators, such as attentional or mnemonic processes, that account for the effects on behavior. In the area of laboratory studies, these mediators are well confirmed (e.g., Gollwitzer \& Sheeran, 2006). However, the concept of planning in health psychological field settings might differ substantially from the original implementation intentions paradigm. For example, as Sniehotta (2009) points out, the implementation intentions paradigm tests the effect of conditional plans (e.g., if situation $x$ is encountered, then I will do $y$ ) on conditional outcomes (e.g., frequency of $y$ shown in situation $x$ ). In contrast, planning studies that aim at changing health behavior outside the laboratory usually report the effects of these conditional plans on unconditional outcomes (e.g., general measure of dietary change).

A consequence of these differences between the original implementation intentions paradigm and planning interventions in field studies might be that mediators through which real-life planning influence behavior change differ substantially from those confirmed within the implementation intentions paradigm (Sniehotta, 2009). One set of potential mediators that might explain effects of planning in field studies on behavior change are the volitional variables specified in the HAPA.

According to the HAPA, volitional variables serve as mediators of planning interventions due to the volitional nature of the planning construct. More precisely, repeated planning interventions might affect self-efficacy by enabling mastery experiences (e.g., Scholz, Sniehotta, Schüz, \& Oeberst, 2007). Moreover, self-reported action and coping planning as a self-administered selfregulatory strategy should be promoted by repeated planning interventions which thereby unfold their effects on behavior change (e.g., Luszczynska et al., 2007). Furthermore, action control is assumed to increase after a repeated planning intervention. Such a repetition may prompt action control subcomponents (self-monitoring and awareness of own standards), which in turn facilitate behavior change (Sniehotta et al., 2005). Finally, intentions might serve as mediators between repeated planning interventions and behavioral change as successful goal attainment stabilizes intentions (e.g., Sniehotta et al., 2005).

\section{AIM OF THE STUDY}

The aim of the present study was twofold: First, to explore how many repetitions of a combined action and coping planning intervention are beneficial for promoting long-term changes to a low-fat diet in overweight and obese individuals; and second, to examine whether the effects of repeated planning interventions are mediated by intentions, self-efficacy, self-reported action planning, self-reported coping planning, and action control.

\section{METHOD}

\section{Sample and procedures}

We conducted a single-blind randomized controlled trial in order to evaluate the effects of different planning interventions on fat consumption and social-cognitive variables 4 (T2), 6 (T3), and 12 months (T4) after baseline assessment. To reach overweight and obese individuals from the general population, the study was advertised in newspapers and on web pages. The advertisement included the logo of the university and read: "For a 


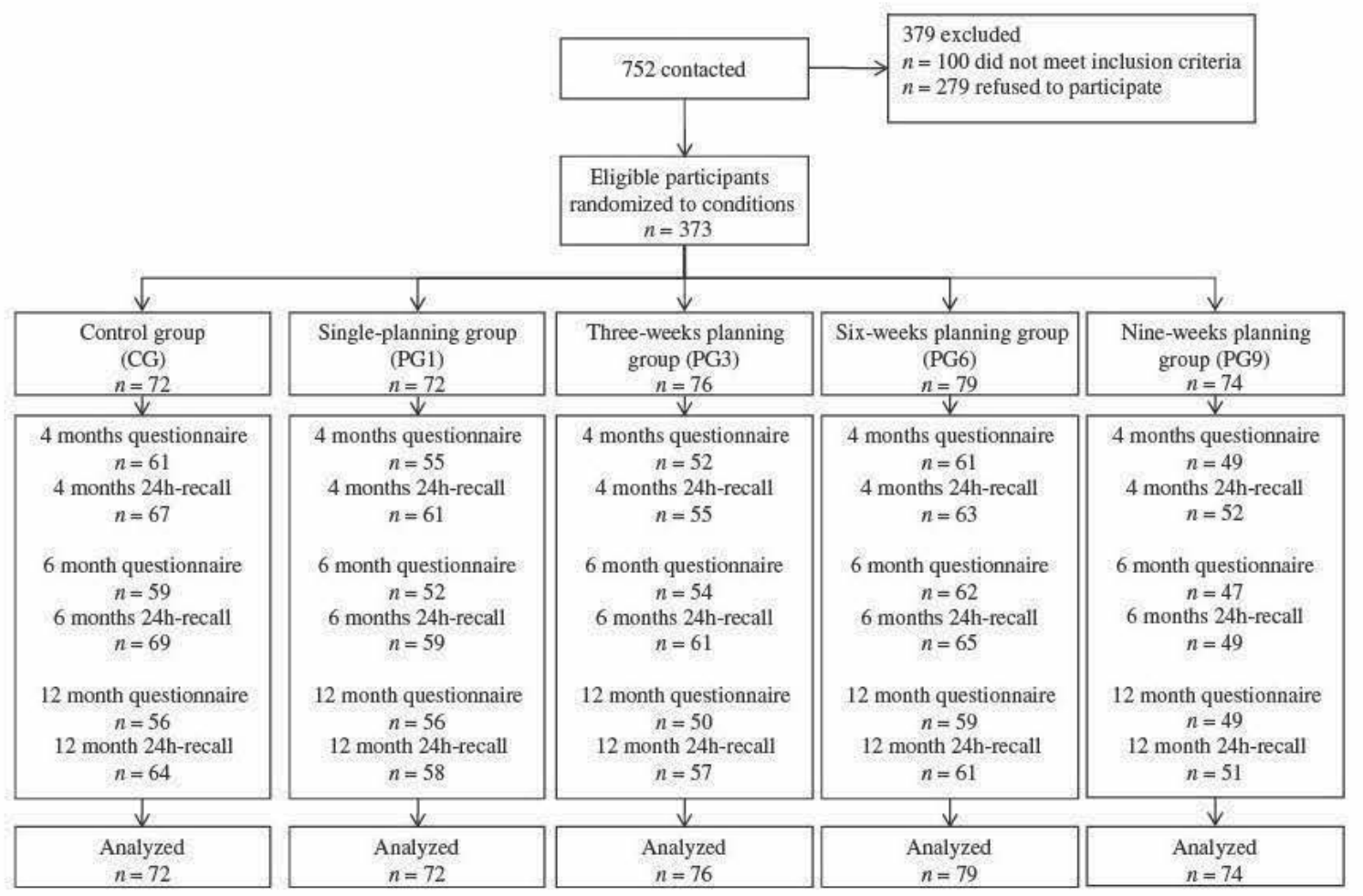

Figure 1. Flow diagram of study participants.

scientific study on changes in diet we are looking for participants who want to reduce their weight." The inclusion criterion that participants had to intend to change their diet was due to the theoretical rationale that planning is assumed to be effective in individuals with strong intentions. Further inclusion criteria were a body mass index (BMI) over 25 and being 18 years or older. Exclusion criteria were participation in a professional weight-loss program (e.g., Weight Watchers) and insufficient comprehension of the German language.

Individuals who called the information line of the study were randomly allocated to one of five groups: a control group, a single-planning group (PG1), a 3 weeks' (PG3), a 6 weeks' (PG6), and a 9 weeks' planning group (PG9) (see Figure 1).

Randomization was unrestricted. Participation was voluntary and all respondents were treated in accordance with the ethical guidelines of the Helsinki Declaration 2000. A reimbursement of 50 Swiss Francs was paid after completion of the study. Follow-up questionnaires together with materials for the $24 \mathrm{~h}$ recall for nutrition assessment and stamped return envelopes were sent by ordinary mail. Parallel to these questionnaires, $24 \mathrm{~h}$ recall telephone interviews on participants' diet were conducted.
Baseline assessment took place in the lab and included informed consent and providing respondents with a personal code to match the data of the questionnaires and $24 \mathrm{~h}$ recalls in order to ensure anonymity. All participants received educational leaflets on a low-fat diet, based on recommendations of the Swiss Society of Nutrition. Next, they completed a self-check knowledge questionnaire on low-fat diet. Subsequently, participants could compare their answers with the correct answers and discuss this with a trained interviewer (see Stadler, Oettingen, \& Gollwitzer, 2009 for a similar procedure). Afterwards, all participants completed the questionnaire including standard questions on demographic information (see sample description). The first $24 \mathrm{~h}$ recall interview was implemented in a face-to-face situation with a trained interviewer. Weight and height were selfreported and objectively measured by experimenters. Finally, all but control group participants received the first planning intervention.

\section{Experimental conditions}

\section{Control group}

Participants completed the baseline assessment as described above as well as all follow-up points 
of measurement, but received no further treatment.

\section{Intervention groups}

In addition to the components of the baseline assessment described above, participants in the single-planning intervention group (PG1) took part in a planning intervention at the end of the baseline session. This planning intervention was adopted from Sniehotta and colleagues (2006) and adapted to the nutrition setting. In a face-to-face situation with an undergraduate psychology student, trained in implementing the intervention by the first author, participants were first instructed to form up to three action plans on their low-fat diet. The planning sheet for action plans started with the instruction, "Please think about when, where and how you plan to comply to a low-fat diet next week. Please write down your three most important plans in the following table. The more precisely, concretely and personally you formulate your plans, the more they can help you." The table contained three rows labeled Plan 1, Plan 2, and Plan 3. The columns were headed "when," "where," and "how." Following this, participants were asked to form up to three coping plans. The planning sheet for coping plans started with the instruction: "Please think carefully about any 'personal risk situations' that might make it difficult for you to comply with your low-fat diet. Make concrete plans on what to do to overcome these personal risk situations. Please write down your three most important plans in the following table. The more precisely, concretely and personally you formulate your plans, the more they can help you." The table again contained three rows labeled Plan 1, Plan 2, and Plan 3. The columns were headed "what personal risk situation?" and "how do you overcome this situation?" At the bottom of both planning sheets, participants read: "Visualize the situations and your planned actions and make a firm commitment to act as planned." The trained interventionists were advised to be positively reinforcing and nondirective. This means they were instructed to only assist participants when plans were not in accordance with the paradigm (e.g., when participants wrote down that they would buy fresh vegetables from the local market, which can be categorized a goal intention but not an action plan).

The PG3, PG6, and PG9 participants also received the face-to-face planning intervention during baseline. Additionally, participants were sent three, six, or nine planning sheets depending on their group allocation starting the week after baseline assessment. Participants were instructed to repeat the planning of a low-fat diet exactly as in the face-to-face planning session every Sunday and to send the planning sheet with a return envelope to the experimenters. For the action plans, the general instruction was "Were all important situations covered by your last plans? If not, please add your new plans here. Or did some plans not work out as intended? Then form a new plan. Or were your plans helpful? Then just repeat them here in order to avoid forgetting them which will facilitate changing your diet." Then the instruction for the formulation of action plans as described above followed. For coping plans, the general instruction was "Were all important risk situations covered by your last plans? If not, please add your new plans here. Or did some plans not work out for overcoming your personal risk situations as intended? Then form a new plan. Or were your plans helpful? Then just repeat them here in order to avoid forgetting them which will facilitate changing your diet." Then the instruction for the formulation of coping plans as described above followed. This procedure was adopted from Sniehottaet al. (2005).

\section{Sample characteristics}

The sample consisted of 373 participants ( $n=270$ women, $72.4 \%$ ) with a mean age of $M=52.42(S D=12.79$, range $=18-82)($ Figure 1$)$. The majority of participants were married $(n=247$, $66.2 \%), 58$ individuals $(15.5 \%)$ were divorced, 51 $(13.7 \%)$ were single, and $16(4.3 \%)$ were widowed; one person $(0.3 \%)$ did not indicate his/her marital status. Most participants reported having attended 9 years of schooling $(n=231,61.9 \%)$, indicating an average educational level of the sample. Mean BMI was $M=31.06(S D=4.41)$.

\section{Dropout analyses}

Overall, dropout ranged between $25.5 \%$ and $27.6 \%$ for the questionnaire and between $18.8 \%$ and $22 \%$ for the $24 \mathrm{~h}$ recalls across the three followups (see Figure 1). As dropout was relatively stable over time, dropout analyses for T4 are reported. No differences between dropouts and continuers emerged for fat consumption, self-efficacy, intentions, action planning, and coping planning. In terms of sociodemographic and control variables, no systematic dropout emerged for gender, education and social desirability. However, dropouts reported lower action control, $M=3.24, S D=.94$ for dropouts, $M=3.54, S D=1.22$ for continuers; $F(1,360)=4.00, \quad p=.046, \eta^{2}=.01 ;$ they were 
TABLE 1

Means, standard deviations, and internal consistency for all constructs of the study $(N=373)$

\begin{tabular}{|c|c|c|c|c|c|c|c|c|c|c|c|c|}
\hline & \multicolumn{3}{|c|}{ Baseline (T1) } & \multicolumn{3}{|c|}{4 months follow up (T2) } & \multicolumn{3}{|c|}{6 months follow up (T3) } & \multicolumn{3}{|c|}{12 months follow up (T4) } \\
\hline & $M$ & $S D$ & $\alpha$ & $M$ & $S D$ & $\alpha$ & $M$ & $S D$ & $\alpha$ & $M$ & $S D$ & $\alpha$ \\
\hline Fat (g) & 77.09 & 34.60 & & 61.89 & 31.74 & & 58.46 & 29.52 & & 64.29 & 30.54 & \\
\hline Intentions & 5.37 & .65 & .82 & 5.06 & .79 & .86 & 5.14 & .73 & .87 & 5.08 & .73 & .86 \\
\hline Self efficacy & 4.59 & 1.18 & .84 & 4.69 & 1.05 & .86 & 4.71 & 1.05 & .85 & 4.68 & 1.09 & .86 \\
\hline Action planning & 4.42 & 1.31 & .84 & 4.71 & 1.07 & .90 & 4.66 & 1.11 & .94 & 4.69 & 1.14 & .95 \\
\hline Coping planning & 3.30 & 1.4 & .85 & 4.03 & 1.21 & .90 & 4.04 & 1.17 & .90 & 4.12 & 1.19 & .91 \\
\hline Action control & 3.50 & 1.17 & .90 & 4.13 & 1.03 & .90 & 4.10 & 1.07 & .93 & 4.08 & 1.08 & .91 \\
\hline Social desirability & 4.81 & 2.60 & .64 & & & & & & & & & \\
\hline
\end{tabular}

younger, $M=48.74, S D=12.35$ for dropouts, $M=53.46, \quad S D=12.77$ for continuers; $F(1$, $370)=8.78, p=.03, \eta^{2}=.02$; and had a higher BMI at baseline than continuers, $M=31.89$, $S D=5.11$ for dropouts, $M=30.74, S D=4.08$ for continuers; $F(1,368)=5.11, p=.024, \eta^{2}=.02$. Moreover, married individuals were less likely and divorced individuals more likely to drop out, $\chi^{2}(3)=8.83, p=.03$. Finally, control group participants tended to be less and PG9 participants were more likely to drop out than to continue study participation, $\chi^{2}(4)=9.24, p=.06$.

\section{Measures}

Means, standard deviations and Cronbach's alphas are displayed in Table 1. Unless otherwise indicated, response format was a six-point Likert scale $(1=$ completely disagree to $6=$ completely agree).

Fat consumption was assessed by $24 \mathrm{~h}$ recalls (Wolper, Heshka, \& Heymsfield, 1995). For the purpose of group comparisons, which were aimed at in the present study, single assessments of $24 \mathrm{~h}$ recalls provide accurate and valid data (e.g., Kubena, 2000; Wolper et al., 1995). In this structured interview participants were asked to report everything they ate and drank during the last day from getting up until going to bed. In addition, it was asked whether participants consumed anything after going to bed. In order to validate the assessment of portion sizes, participants received a standardized picture book with portion sizes at all assessments. Moreover, in order to improve accuracy of reports of food eaten, questions on the context of eating occasions were included in the interview (Armstrong et al., 2000). Data were analyzed with a nutrition analysis program (EBISPro) which resulted in total amount of fat consumed $(\mathrm{g})$ per $24 \mathrm{~h}$ recall.

Behavioral intentions were measured by six items (adapted from Scholz, Nagy, Göhner,
Luszczynska, \& Kliegel, 2009); for example: “I intend to eat a low-fat diet (e.g., low-fat meat, cheese, etc.)."

Self-efficacy was assessed by three items (adapted from Scholz et al., 2009); for example: "I am confident that I can return to a low-fat diet, even if I have relapsed several times."

Action planning was assessed by four items (Scholz et al., 2009); for example: "I have made a detailed plan regarding when (at what meals) to change my eating habits."

Coping planning was assessed by five items (adapted from Sniehotta et al., 2005); for example: "I have made a detailed plan regarding what to do when I crave high-fat food (e.g., chocolate)."

Action control was measured by nine items and adapted from Sniehotta et al. (2005). The item stem "During the past four weeks" was followed by items such as "I closely monitored my eating behavior"; "I had my intentions to change my eating habits often on my mind"; and "I tried my best to act in accordance with my intentions."

Social desirability was assessed by the SDS-17 (Stoeber, 2001) and served as control variable. It was assessed at Time 1 only. Answering format was dichotomous (1 no, 2 yes). Higher values indicated higher social desirability.

\section{Data analyses}

As dropout turned out to be systematically biased (i.e., missing pattern was missing at random (MAR), meaning that missingness depends on observed data but not on unobserved data; Graham, 2009), we accounted for missing data by employing expectation maximization (EM; Graham, 2009). Univariate and multivariate outliers were routinely screened and treated as suggested by Tabachnick and Fidell (2001). Main analyses were repeated measures ANCOVAs 
TABLE 2

Correlations of main study variables with potential control variables

\begin{tabular}{|c|c|c|c|c|}
\hline & $B M I$ & $\begin{array}{c}\text { Social } \\
\text { desirability }\end{array}$ & Age & Sex \\
\hline Fat T1 & .01 & $.11^{*}$ & $.15^{*}$ & $.14^{*}$ \\
\hline Fat T2 & .02 & .09 & .10 & $.20 * *$ \\
\hline Fat T3 & .01 & .10 & $.17 *$ & $.12 *$ \\
\hline Fat T4 & .03 & $.16^{*}$ & $.10^{*}$ & $.16^{*}$ \\
\hline Intentions $\mathrm{T} 1$ & .03 & $.21 * *$ & $.13^{*}$ & $.18^{* *}$ \\
\hline Intentions $\mathrm{T} 2$ & .09 & $.20 * *$ & $.15^{*}$ & $.12 *$ \\
\hline Intentions T3 & .03 & $.19 * *$ & $.18^{*}$ & $.10^{*}$ \\
\hline Intentions $\mathrm{T} 4$ & .07 & $.22 * *$ & $.20^{* *}$ & $.13^{*}$ \\
\hline Self efficacy T1 & .10 & .03 & $.16^{*}$ & .04 \\
\hline Self efficacy T2 & .07 & .002 & $.12 *$ & .03 \\
\hline Self efficacy T3 & .07 & .07 & $.17 *$ & .05 \\
\hline Self efficacy T4 & .10 & .03 & $.20 * *$ & .02 \\
\hline AP T1 & $.13^{*}$ & .10 & .08 & $.12^{*}$ \\
\hline AP T2 & .05 & .09 & $.20 * *$ & .04 \\
\hline AP T3 & .04 & .08 & $.16^{*}$ & .02 \\
\hline AP T4 & .01 & .09 & $.27 * *$ & .04 \\
\hline CP T1 & .09 & $.19 * *$ & $.14^{*}$ & .04 \\
\hline $\mathrm{CP} \mathrm{T} 2$ & .01 & $.23^{* *}$ & $.23^{* *}$ & .02 \\
\hline CP T3 & .03 & $.17 * *$ & $.20^{* *}$ & .001 \\
\hline CP T4 & .01 & $.18 * *$ & $.30 * *$ & .03 \\
\hline AC T1 & .06 & $.15^{*}$ & .07 & .07 \\
\hline $\mathrm{AC} \mathrm{T} 2$ & .004 & $.15^{*}$ & $.19^{* *}$ & .04 \\
\hline AC T3 & .02 & .09 & $.16^{*}$ & .03 \\
\hline AC T4 & .09 & $.12 *$ & $.24 * *$ & .03 \\
\hline
\end{tabular}

Sex coded 1, women; 2, men. AP=action planning, $\mathrm{CP}=$ coping planning, $\mathrm{AC}=$ action control.

across the four points of measurement with the target variable as within-subjects factor, intervention group as between-subjects factor, and control variables as covariates. In case of a significant violation of the assumption of sphericity, Greenhouse-Geisser corrections were applied (Tabachnick \& Fidell, 2001). All analyses were conducted with SPSS 17.

Power was high for detecting within-between interactions in repeated-measures ANOVAs: power $=.97$, critical $F(12,1104)=1.86, p<.05$, small effect $=.10$ (Erdfelder, Lang, \& Buchner, 2007).

\section{RESULTS}

\section{Randomization check}

A one-way ANOVA did not reveal any significant differences between the control group and the intervention groups on $\mathrm{T} 1$ fat consumption, social desirability, BMI, the social-cognitive variables included in the study, or age. Likewise, using $\chi^{2}$ tests, no differences on the demographic variables (sex, marital status, education) were found.

\section{Descriptives}

Correlations with the potential control variables, BMI, social desirability, age, and sex are displayed in Table 2. Fat consumption as well as most socialcognitive variables were correlated with age and social desirability. Sex was only related to fat consumption and intentions and T1 action planning, indicating that men consumed more fat and reported lower intentions across the four points of measurement and lower T1 action planning. Control variables were included in the analyses whenever significant correlations emerged with the target variable at any point of measurement.

The correlation of the objectively measured and the self-reported BMI was $r=.98, p<.001$, indicating a high validity of self-reported BMI.

\section{Change in fat consumption}

For analyzing change in fat consumption, a repeated measures ANCOVA was run with fat consumption as within-subjects factor, intervention group as between-subjects factor, and social desirability, age, and sex as control variables. No effects for any control variable emerged (all $F$ values below 1.2; all $p$ values above .29). For the main outcome fat consumption, no significant effects for time, $F(2.93,1067.18)=1.09, p=.35$, partial $\left.\eta^{2}=.003\right)$, nor for time $\times$ group, $F(11.73$, $1067.18)=1.19, p=.29$, partial $\eta^{2}=.01$, emerged. Thus, the interventions failed to promote low fat consumption in all groups.

With this nonsignificant result on the main outcome, examination of potential mediators is obsolete. In the following, effects of the interventions on social-cognitive variables are reported nonetheless as a promotion of these variables would indicate a positive effect of the interventions per se, albeit not the main purpose.

\section{Change in self-efficacy and intentions}

The analysis of change in self-efficacy included age as control variable. The effect of age, however, was not significant, $F(2.57,940.75)=0.80, p=.48$, partial $\eta^{2}=.002$. Self-efficacy for the total sample did not change significantly over time, $F(2.57$, $940.75)=0.99, p=.39$, partial $\eta^{2}=.003$. This, however, was qualified by group (time $\times$ group: $F(10.28,940.75)=2.31, p=.01$, partial $\left.\eta^{2}=.03\right)$, indicating that the interventions were differently effective for fostering self-efficacy across time. Figure 2 displays the time $\times$ group interaction. Post-hoc analyses revealed that significant 


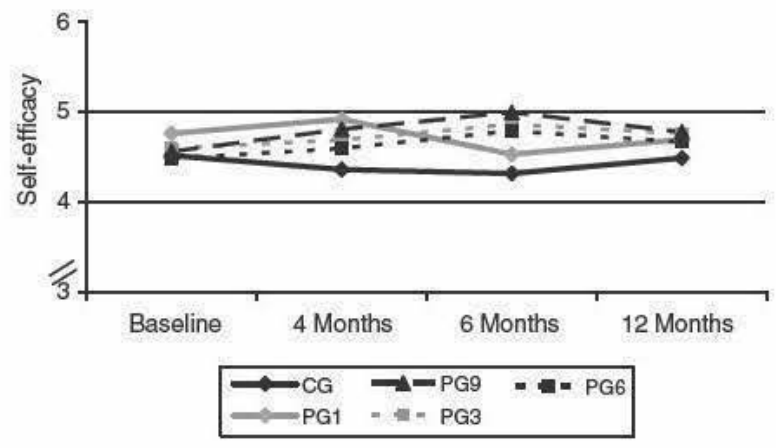

Figure 2. Time $\times$ group interaction on self efficacy across the 12 month period. Original scale from 1 to $6 . \mathrm{CG}=$ control group, $\mathrm{PG1}=$ single planning group, $\mathrm{PG} 3=3$ weeks' planning group, PG6 $=6$ weeks' planning group, PG9 $=9$ weeks' planning group.

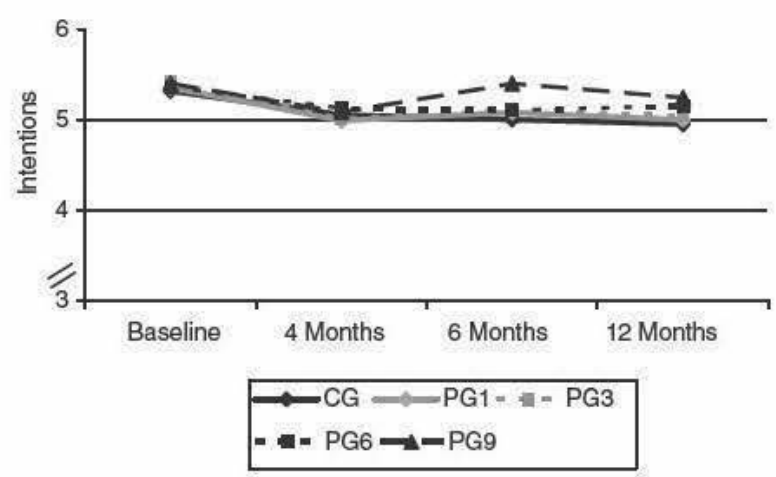

Figure 3. Time $\times$ group interaction on intentions across the 12 month period. Note. Original scale from 1 to $6 . \mathrm{CG}=$ control group, $\mathrm{PGI}=$ single planning group, $\mathrm{PG} 3=3$ weeks' planning group, PG6 $=6$ weeks' planning group, PG9 $=9$ weeks' planning group.

differences between groups emerged between control group participants $(M 1=4.49, M 2=4.36$, $M 3=4.30, M 4=4.50)$ and PG9 $(M 1=4.51$, $M 2=4.79, \quad M 3=4.96, \quad M 4=4.77 ; \quad F(2.66$, $379.65)=3.92, p=.01$, partial $\left.\eta^{2}=.03\right)$; between PG1 $\quad(M 1=4.75, \quad M 2=4.93, \quad M 3=4.53$, $M 4=4.73)$ and PG3 participants $(M 1=4.62$, $M 2=4.68, \quad M 3=4.87, \quad M 4=4.73 ; \quad F(2.59$, $373.26)=2.82, \quad p=.047$, partial $\left.\eta^{2}=.02\right) ;$ PG1 and PG6 participants $(M 1=4.56, M 2=4.62$, $M 3=4.84, \quad M 4=4.68 ; \quad F(2.42, \quad 356.10)=3.97$, $p=.01$, partial $\eta^{2}=.03$ ), and PG1 and PG9 participants, $F(2.48,355.11)=5.02, p=.004$, partial $\eta^{2}=.03$. In sum, all repeated planning groups seemed to benefit from the intervention in terms of their self-efficacy. This was especially pronounced for the 9 weeks' planning group (PG9).

The analysis of change in intentions included social desirability, age, and sex as control variables. None of the covariates resulted in a significant effect (all $F$ values $<1.1, p$ values $>.35$ ). The repeated measures ANCOVA resulted in a significant within-subjects (i.e., time) effect, $F(2.88$, $1048.63)=4.37, \quad p=.005, \quad$ partial $\eta^{2}=.01$. Moreover, a significant time $\times$ group effect emerged, $F(11.52,1048.63)=1.95, p=.03$, partial $\eta^{2}=.02$, indicating that the interventions differently affected intentions across time. Figure 3 displays the time $\times$ group interaction. Post-hoc analyses revealed that the only significant differences between groups were between control group participants $(M 1=5.33, M 2=5.05, M 3=5.00$, $M 4=4.95)$ and PG9 $(M 1=5.39, M 2=5.06$, $M 3=5.38, \quad M 4=5.22 ; \quad F(2.77, \quad 390.0)=4.70$, $p=.04$, partial $\eta^{2}=.03$ ) and between PG6 $(M 1=5.38, \quad M 2=5.15, \quad M 3=5.13, \quad M 4=5.18)$ and PG9 $(F(2.61,383.05)=3.11, p=.03$, partial $\eta^{2}=.02$ ). PG9 participants seem to be the group that managed best to keep their intentions on a stable high level over time.

\section{Change in action control, action planning, and coping planning}

The analysis of change in action control included social desirability and age as control variables. Age displayed a significant effect, $F(2.70,986.24)=$ 2.90, $p=.04$, partial $\eta^{2}=.008$, whereas social desirability did not, $F(2.70,986.24)=.58, p=.61$, partial $\eta^{2}=.002$. The repeated measures ANCOVA resulted in a nonsignificant time effect, $F(2.70,986.24)=.23, p=.86$, partial $\eta^{2}=.001$, as well as a nonsignificant time $\times$ group effect, $F(10.81,986.24)=.77,=.67$, partial $\eta^{2}=.008$. Thus, contrary to our expectations, the interventions did not promote action control over time.

For action planning, repeated measures ANCOVA included BMI, age, and sex as control variables. Age emerged as a significant covariate, $F(2.27,828.98)=3.30, p=.03$, partial $\eta^{2}=.009$, whereas BMI and sex were not significant, $F(2.27$, $828.98)=2.18, p=.11$, partial $\eta^{2}=.006$ for BMI; $F(2.27,828.98)=1.85, p=.15$, partial $\left.\eta^{2}=.005\right)$. Results indicated no significant change over time, $F(2.27,828.98)=.06, p=.96$, partial $\eta^{2}=.000$, nor a time $\times$ group interaction, $F(9.11,828.98)=.79$, $p=.63$, partial $\eta^{2}=.009$. Thus, again contrary to our assumptions, action planning could not be differentially promoted by the interventions.

For change in coping planning, a repeated measures ANCOVA was run with social desirability and age as control variables. Age was significant on the $10 \%$ level, $F(2.30$, $840.03)=2.70, p=.06$, partial $\eta^{2}=.007$, whereas social desirability did not gain significance, $F(2.30$, 


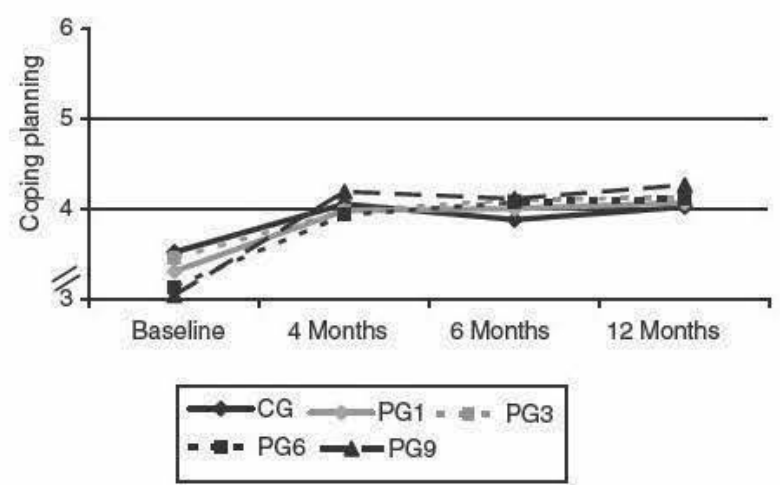

Figure 4. Time $\times$ group interaction on coping planning across the 12 month period. Note. Original scale from 1 to 6 . $\mathrm{CG}=$ control group, $\mathrm{PG1}=$ single planning group, $\mathrm{PG} 3=3$ weeks' planning group, PG6 $=6$ weeks' planning group, PG9 $=9$ weeks' planning group.

$840.03)=.72, p=.51$, partial $\eta^{2}=.002$. For the total sample, coping planning did not change significantly over time, $F(2.30,840.03)=1.54$, $p=.20$, partial $\left.\eta^{2}=.004\right)$. This, however, was qualified by group: $F(9.21,840.03)=2.08, p=.03$, partial $\eta^{2}=.02$ for the time $\times$ group interaction. Figure 4 displays the time $\times$ group interaction. Post-hoc analyses revealed that the only significant differences between groups were between control group participants $(M 1=3.49, \quad M 2=4.03$, $M 3=3.90, \quad M 4=4.04)$ and PG6 $(M 1=3.21$, $M 2=3.99, \quad M 3=4.07, \quad M 4=4.12 ; \quad F(2.36$, $344.93)=3.11, p=.04$, partial $\eta^{2}=.02$ ), control group participants and PG9 $(M 1=3.01$, $M 2=4.16, \quad M 3=4.13, \quad M 4=4.26 ; \quad F(2.26$, $320.99)=6.10, p=.002$, partial $\left.\eta^{2}=.04\right)$, and between PG3 $(M 1=3.48, M 2=3.98, M 3=4.06$, $M 4=4.06)$ and PG9 participants $(F(2.18$, $316.50)=5.61, p=.003$, partial $\eta^{2}=.04$ ). Thus, in line with our expectations, coping planning could be differentially promoted by repeated planning interventions. Again, PG9 seems to be the group with the most consistent effects.

\section{DISCUSSION}

This study aimed to test whether there is a critical number of repetitions in planning interventions in order to promote long-term changes in fat intake. Second, we investigated the role of social-cognitive variables as potential mediators of the interventions-behavior change associations. Results disconfirm the assumption that long-term changes in fat intake can be promoted by repeated planning interventions, as none of the intervention groups lowered their fat consumption across the 12 months. Hence, mediator testing was obsolete.
Follow-up analyses, however, revealed effects of the interventions on social-cognitive variables. In line with our hypotheses, effects were found for intentions, self-efficacy, and coping planning. No effects, however, emerged for action planning and action control, which was in contrast to our assumptions. With regard to the different interventions, the 9 weeks' planning group (PG9) produced the most consistent effects. Effect sizes, however, were very small and thus results need to be replicated and interpreted with caution.

This study is not the only one that could not find an effect of planning interventions on subsequent behavior change (e.g., Jackson et al., 2005; Rutter, Steadman, \& Quine, 2006; Skar, Sniehotta, Molloy, Prestwich, \&, Araujo-Soares, 2011). There are several plausible explanations for this non-effect. First, it is possible that participants did not adhere to the intervention protocol (cf. Rutter et al., 2006). We were able to rerun the analyses with only those participants of the weekly planning groups who strictly adhered to our instructions and sent back three, six, or nine planning sheets (for PG3: $n=47$, PG6: $n=54$, and PG9: $n=40$, respectively). As our intervention at baseline was a face-to-face format, all participants from the PG1 formed at least one action and one coping plan during the baseline intervention. Thus, adherence in this group was guaranteed. Results of the analyses with adherent participants did not differ from those with all participants included. Thus, nonadherence to protocol does not explain the lack of the intervention effects.

This is in line with a study by Skar, Sniehotta, Molloy, Prestwich, \& Araujo-Soares (2011), who pointed that the quality of the plans may affect obtained results. In order to test for this potential explanation, a rating system of plans would be needed. The quality of plans and in the same respect the adherence to the intervention protocol remains a major challenge for field studies: Plans formed without assistance of the experimenter are rather likely to depart from the original planning paradigm and thus effectiveness might be reduced substantially. There are, however, several studies applying similar "open-plan" designs and demonstrating that planning interventions are effective, even if quality of plans is not accounted for (e.g., Gollwitzer \& Sheeran, 2006). Thus, this might partly but not fully explain the lack of an effect in the present study.

A third explanation is the content of the plans. For complex behavior changes, such as reducing one's fat consumption, there are several ways to succeed (de Vet, 2007): A person can exchange a portion of chips for vegetables, stop eating 
chocolate or eat only half of the usual portion size. It remains unknown what plan content is most effective for this specific behavior change and whether this is further moderated by psychosocial variables. The content and extent of baseline education may also influence the content of the plans. The present study applied a brief nutrition education. By contrast, research showing significant effects of a planning intervention on saturated fat intake was conducted among patients who participated in a comprehensive nutrition education program (Luszczynska et al., 2007). Future studies should identify whether content of plans is a critical factor for the effectiveness of complex behavior change.

Fourth, as Sniehotta (2009) points out, the effects of conditional plans (e.g., "If I crave chocolate, I will eat a banana instead") on unconditional outcomes (e.g., a general measure of fat consumption, typical of field studies, also applied in the present study) are assumed to be smaller than effects of planning found in the laboratory where the effects of conditional plans (e.g., if situation $x$ is encountered, I will do $y$ ) are evaluated by conditional outcomes (e.g., frequency of $y$ shown in situation $x$ ). Thus, together with the rather long time span, this might constitute a further explanation for the lack of an effect. A final explanation might be that complex behavior change in a population of individuals that are overweight or obese for a very long time and thus have a strong habitual eating behavior is not easily promoted by a planning intervention alone. This is in line with the rather disappointing results of large trials targeting several behaviors in order to promote weight loss (for an overview see, e.g., Mann et al., 2007).

In terms of changes in psychosocial variables, the effect on intentions was in line with earlier studies (Sniehotta et al., 2005): Especially for the 9 weeks' planning group (PG9) a maladaptive decrease of intentions was avoided. This is of particular importance as instability of intentions has been found to be detrimental for behavioral change (e.g., Sheeran \& Abraham, 2003).

Against our hypotheses, action planning was not promoted by any of the planning interventions. Failure to promote action planning by a planning intervention has also been reported in other studies (e.g., Sniehotta et al., 2005). In the present study participants' self-reported frequency of action planning was already quite high and thus could not be further promoted by the intervention.

Also, for action control neither a time nor a time $\times$ group interaction was found. The non-effect on action control for the repeated planning intervention groups is in contrast to other studies applying a repeated planning intervention (e.g., Sniehotta et al., 2005). However, participants in the present study were not instructed to indicate on a weekly basis whether they had indeed acted on their plans of the past week. Such instructions were used by Sniehotta et al. (2005). Instead we only asked participants to plan again every week. Thus, action control might not have been promoted explicitly enough by the present repeated planning interventions. Future studies that aim at promoting action control together with planning should thus include stronger action control treatments.

Positive effects on self-efficacy and coping planning were in line with our expectations. In terms of self-efficacy, social-cognitive theory postulates that the most important source of selfefficacy is mastery experience (Bandura, 1997). As recent research shows, mastery experience (indicated by successful behavior change) seems to be triggered by planning, which in turn promotes higher self-efficacy (Scholz et al., 2007). The fact that we did not find an effect of the experimental treatment on fat consumption (as an indicator of mastery experience) is not necessarily a contradiction to this interpretation, as we did not have a direct measure of mastery in this study. To fully comprehend these associations between mastery, self-efficacy, and planning, mastery experience should be assessed directly and not only via behavior as an indicator.

The present study provides cautious hints that a repeated planning intervention of relatively high intensity ( 9 weeks) can promote coping planning as a self-regulatory strategy up to 1 year later. Yet all effects in the present study were very small and are thus to be interpreted cautiously. Nonetheless, it is a strength of the present study that the effects of the interventions on social-cognitive variables were examined (cf. Michie \& Abraham, 2004). Moreover, these findings bear some practical implications. As the group with the highest number of repetitions of the planning intervention (PG9) reported the most beneficial effects, this can be cautiously interpreted as a hint that planning repeatedly for at least 9 times results in more positive outcomes in social-cognitive variables compared to not planning. Thus, in terms of the social-cognitive variables this study's results emphasize the idea that planning should be integrated in people's daily life in that plans should either be repeated or adapted when needed on a regular basis. 
Overall, this study provides evidence that a single planning intervention as well as different repeated planning interventions was not able to promote changes in the complex behavior of fat consumption across a period of 12 months among overweight and obese individuals. Future studies should address the compliance of participants to the study protocol with regard to the final quality of self-formed plans in more detail in order to advance our knowledge of the applicability and efficacy of the planning paradigm in the context of long-term changes in complex behaviors.

\section{REFERENCES}

Ajzen, I. (1991). The theory of planned behavior. Organizational Behavior and Human Decision Processes, 50, 179211.

Armitage, C. J. (2004). Evidence that implementation intentions reduce dietary fat intake: A randomized controlled trial. Health Psychology, 23, 319323.

Armstrong, A. M., MacDonald, A., Booth, I. W., Platts, R. G., Knibb, R. C., \& Booth, D. A. (2000). Errors in memory for dietary intake and their reduction. Applied Cognitive Psychology, 14, 183191.

Bandura, A. (1997). Self efficacy: The exercise of control. New York, NY: Freeman.

Chapman, J., \& Armitage, C. J. (2010). Evidence that boosters augment the long term impact of implemen tation intentions on fruit and vegetable intake. Psychology and Health, 25, 365381.

De Vet, E. (2007). Implementation intentions and diet. Journal of Psychosomatic Research, 63, 499500.

Erdfelder, F. F. E., Lang, E., \& Buchner, A. (2007). G*Power 3: A flexible statistical power 535 analysis program for the social, behavioural, and biomedical sciences. Behaviour Research Methods, 39, 175191.

Gollwitzer, P. M., \& Sheeran, P. (2006). Implementation intentions and goal achievement: A meta analysis of effects and processes. Advances in Experimental Social Psychology, 38, 69119.

Graham, J. W. (2009). Missing data analysis: Making it work in the real world. Annual Review of Psychology, 60, 549576 .

Jackson, C., Lawton, R., Knapp, P., Raynor, D. K., Conner, M., \& Lowe, C. (2005). Beyond intention: Do specific plans increase health behaviours in patients in primary care? A study of fruit and vegetable consumption. Social Science and Medicine, 60, 23832391.

Kubena, K. S. (2000). Accuracy in dietary assessment: On the road to good science. Journal of the American Dietetic Association, 100, 775776.

Kumanyika, S. K., Van Horn, L., Bowen, D., Perri, M. G., Rolls, B. J., Czajkowski, S. M., et al. (2000). Maintenance of dietary behavior change. Health Psychology, 19, 4256.
Luszczynska, A., \& Hayes, C. (2009). Changing nutri tion, physical activity and body weight among student nurses and midwives: Effects of a planning intervention and self efficacy beliefs. Journal of Health Psychology, 14, 10751084.

Luszczynska, A., Scholz, U., \& Sutton, S. (2007). Planning to change diet: A randomized controlled trial of an implementation intentions training inter vention to reduce saturated fat intake after myocar dial infarction. Journal of Psychosomatic Research, 63, 491497.

Mann, T. A., Tomiyama, J., Westling, E., Lew, A. M., Samuels, B., \& Chatman, J. (2007). Medicare's search for effective obesity treatments: Diets are not the answer. American Psychologist, 62, 220233.

Michie, S., \& Abraham, C. (2004). Interventions to change health behaviors: Evidence based or evidence inspired? Psychology \& Health, 19, 2951.

National Institutes of Health (1998). Clinical guidelines on the identification, evaluation, and treatment of overweight and obesity in adults. NIH Publication 98 4083. Bethesda, MD: NIH.

Prestwich, A., Ayres, K., \& Lawton, R. J. (2008). Crossing two types of implementation intentions with a protection motivation intervention for the reduc tion of saturated fat intake: A randomized trial. Social Science \& Medicine, 67, 15501558.

Prestwich, A., Perugini, M., \& Hurling, R. (2010). Can implementation intentions and text messages pro mote brisk walking? A randomized trial. Health Psychology, 29, 4049.

Rutter, D. R., Steadman, L., \& Quine, L. (2006). An implementation intentions intervention to increase uptake of mammography. Annals of Behavioral Medicine, 32, 127134.

Scholz, U., Knoll, N., Sniehotta, F. F., \& Schwarzer, R. (2006). Physical activity and depressive symptoms in cardiac rehabilitation: Long term effects of a self management intervention. Social Science \& Medicine, 62, 31093120.

Scholz, U., Nagy, G., Göhner, W., Luszczynska, A., \& Kliegel, M. (2009). Changes in self regulatory cogni tions as predictors of changes in smoking and nutrition behaviour. Psychology \& Health, 24, 545561.

Scholz, U., Sniehotta, F. F., Schüz, B., \& Oeberst, A. (2007). Dynamics in self regulation: Plan execution self efficacy and mastery of action plans. Journal of Applied Social Psychology, 37, 27062725.

Schwarzer, R. (2008). Modeling health behavior change: How to predict and modify the adoption and maintenance of health behaviors. Applied Psychology, 57, 129.

Sheeran, P., \& Abraham, C. (2003). Mediator of moderators: Temporal stability of intention and the intention behaviour relation. Personality and Social Psychology Bulletin, 29, 205215.

Skar, S., Sniehotta, F. F., Molloy, G. J., Prestwich, A., \& Araujo Soares, V. (2011). Do brief online planning interventions increase physical activitiy amongst university students? A randomized controlled trial. Psychology and Health, 26, 399417.

Sniehotta, F. F. (2009). Towards a theory of intentional behaviour change: Plans, planning and self regula tion. British Journal of Health Psychology, 14, 261273. 
Sniehotta, F. F., Scholz, U., \& Schwarzer, R. (2006). Action plans and coping plans for physical exercise: A longitudinal intervention study in cardiac rehabi litation. British Journal of Health Psychology, 11, 2337.

Sniehotta, F. F., Scholz, U., Schwarzer, R., Fuhrmann, B., Kiwus, U., \& Völler, H. (2005). Long term effects of two psychological interventions on physical exercise and self regulation after coronary rehabilita tion. International Journal of Behavioral Medicine, 12, 244255.

Stadler, G., Oettingen, G., \& Gollwitzer, P. M. (2009). Physical activity in women: Effects of a self regula tion intervention. American Journal of Preventive Medicine, 36, 2934.
Stoeber, J. (2001). The Social Desirability Scale 17 (SDS 17): Convergent validity, discriminant validity, and relationship with age. European Journal of Psychological Assessment, 17, 222232.

Tabachnick, B. G., \& Fidell, L. S. (2001). Using multivariate statistics (4th ed.). Boston, MA: Allyn and Bacon.

World Health Organisation (2000). Obesity: Preventing and managing the global epidemic: Report of a WHO consultation. Geneva, Switzerland: WHO.

Wolper, C., Heshka, S., \& Heymsfield, S. B. (1995). Measuring food intake: an overview. In D. B. Allison (Ed.), Handbook of assessment methods for eating behaviors and weight related problems (pp. 215 240). London, UK: Sage. 